\title{
Rehabilitation Protocols for Calcaneus Fractures
}

\author{
Bibek Adhya ${ }^{1}$, Himmat Dhillon ${ }^{2}$, Sidak Dhillon ${ }^{3}$, Mandeep Singh Dhillon ${ }^{4}$
}

\begin{abstract}
Calcaneus fractures are a complex injury. Since the calcaneus plays a key role in weight-bearing and gait cycle, rehabilitation after injury needs to be individualized, and a structured program needs to be implemented. The rehabilitation protocol also varies depending on the type of injury, the associated injuries, and the management of the injury itself, be it surgical or conservative. It is important to understand that mobilization starts much earlier than weight-bearing. The nonweight-bearing time period also differs from patient to patient as that too depends on the type of approach that has been taken to manage the injury. That being said, weight-bearing is very important to minimize reflex sympathetic dystrophy syndrome and osteopenia, so the patients should be encouraged to start weight-bearing as soon as possible. Protocols will differ between patients having bilateral and unilateral calcaneal fractures. The structuring of the rehabilitation program according to the patients' needs is what is essential to ensure good outcomes and will determine the return to activity and work. Stress fractures are a unique problem, and periodization of rehabilitation is the key.
\end{abstract}

Keywords: Calcaneus, Fracture-rehabilitation, Physiotherapy, Return to function.

Journal of Foot and Ankle Surgery (Asia Pacific) (2020): 10.5005/jp-journals-10040-1131

Fractures of the calcaneus are potentially so variable and complex that it is important to classify them and get some idea what the best treatment is for each subtype. The most common injuries, and often the most disabling, are the displaced intra-articular fractures (DIACFs), which are often the most difficult to rehabilitate. ${ }^{1-4}$ The calcaneus plays a key role in weight-bearing and is responsible for the transfer of weight-bearing forces through the ankle to the ground during standing, walking, and even running. Therefore, the most important aim of rehabilitation is to first get back painless locomotion. At the time of fracture, the patient is immediately aware of significant pain and is unable to weight bear on the foot involved. Pain is often severe and unpleasant, with significant swelling around the heel and ankle. Fractures of calcaneus are often comminuted and are also often bilateral, making the postinjury rehabilitation much more complex; additionally, they may be associated with spinal trauma, or other musculoskeletal injuries, or even polytrauma, making it difficult for the physiotherapist to design a standard weight-bearing and post-injury walking protocol applicable to all patients equally. The rehabilitation aims are to minimize stiffness, to prevent reflex sympathetic dystrophy, and early ambulation, all of which helps to minimize other complications. ${ }^{1}$

\section{Aims and Goals of Rehabilitation}

Except for peripheral fractures, all other central fractures involve the subtalar joint, leading to varying degrees of arthritis or even fibrotic stiffness in the subtalar joint. Functional outcomes vary and often depend upon initial degree of displacement or surgical reconstruction; although most patients make an excellent recovery, returning to a preinjury level of activity can prove to be hard for many. Appropriate rehabilitation helps to minimize the complications and ensure early return to normal function.

Return to activity or sport (in case of sports person) can vary from a few weeks to months depending on the type of injury and the treatment provided for the same. In both, operative and nonoperative cases, the rehabilitation needs to be a collaborated effort between the surgeons and the physiotherapists.
${ }^{1}$ Department of Physical and Rehabilitation Medicine, Postgraduate Institute of Medical Education and Research, Chandigarh, India

${ }^{2}$ Department of Physiotherapy, Flinders University, Adelaide, Australia ${ }^{3}$ Department of Orthopaedics, Government Multispeciality Hospital, Chandigarh, India

${ }^{4}$ Department of Orthopaedics, Postgraduate Institute of Medical Education and Research, Chandigarh, India

Corresponding Author: Sidak Dhillon, Department of Orthopaedics, Government Multispeciality Hospital, Chandigarh, India, e-mail: sidakdh@gmail.com

How to cite this article: Adhya B, Dhillon H, Dhillon $\mathrm{S}$, et al. Rehabilitation Protocols for Calcaneus Fractures. J Foot Ankle Surg (Asia Pacific) 2020;7(2):77-82.

Source of support: Nil

Conflict of interest: None

\section{Conservative Treatment and ReHABILITATION}

As the calcaneus plays a key part in the foot biomechanics, the management needs to be planned accordingly. ${ }^{2}$ Most extraarticular fractures, if not displaced, can be managed conservatively. Intra-articular fractures usually require surgical fixation. Some fractures may be intra-articular and severely comminuted. These cases are also managed nonoperatively as surgical fixation is usually unsuccessful. ${ }^{3}$ The recovery and outcome in such cases is different from the others, and this needs to be communicated to the patients.

\section{Rehabilitation}

General consensus states that the patient should be immobilized with a below-knee nonweight-bearing cast for 2 weeks followed by range-of-motion (ROM) exercises. Nevertheless, newer thinking has changed the concept from initial casting to either compressive

(0) The Author(s). 2020 Open Access This article is distributed under the terms of the Creative Commons Attribution 4.0 International License (https://creativecommons. org/licenses/by-nc/4.0/), which permits unrestricted use, distribution, and non-commercial reproduction in any medium, provided you give appropriate credit to the original author(s) and the source, provide a link to the Creative Commons license, and indicate if changes were made. The Creative Commons Public Domain Dedication waiver (http://creativecommons.org/publicdomain/zero/1.0/) applies to the data made available in this article, unless otherwise stated. 
bandages or removable braces so that ankle ROM exercises can be initiated at the earliest. This also allows the application of ice, which helps in reduction of swelling.

Range-of-motion exercises are encouraged early in the rehabilitation, even in surgically treated cases and depending on type of skin incision can start within 3 days (MIS) or 10-12 days after surgery, when the extensile surgical incision has begun healing. It is very important to have a well-fitting orthosis (back slab to minimize equinus) for the sake of comfort and to prevent contractures of the gastrocnemius and soleus. Suture removed at 2-3 weeks, but weight-bearing is delayed for up to 12 weeks, depending on the original degree of comminution and the subsequent rigidity of the fixation.

The debate still arises on the proper management of calcaneal fractures after operative management. As per Bohler et al., surgical repair should be followed by traditional immobilization, while Essex-Lopresti et al., support early mobilization protocols, within 24-72 hours of surgical reconstruction. ${ }^{4-10}$ Different views on the preferable management of calcaneal fractures after initial nonoperative management also exist. Barnard proposes the use of traditional immobilization in the form of a short leg cast, while Lance et al. recommend early mobilization with nonoperative management. ${ }^{11}$ Whatever the thought process, progressive weightbearing should not begin before 8 weeks to minimize the chances of late articular collapse, graduating to weight-bearing by 12 weeks.

\section{Protocol for Nonoperatively Managed Patients $^{12}$ \\ Weeks 1-4 \\ Goal}

Pain and edema control: prevent further worsening of fracture or loss of surgical stabilization. Maintain function and cardiovascular endurance.

\section{Intervention}

Cast with ankle in neutral and sometimes slight eversion. Other option is removable brace or compressive bandages.

Elevation with ankle maintained at $90^{\circ}$ in relation to the tibia. Cryo-compression or removable splints can be used.

Hours 24-72, active range of motion exercises, with movement at tibiotalar, subtalar, midtarsal, and toe joints every hour. Toe flexion is important to prevent contractures and swelling. Compartment syndrome is rare but should always be kept in mind.

Days 2-4, nonweight-bearing walking with crutches or walker.

After 14 days, proper fitting and usage of surgical shoe or orthosis to prevent contracture (Fig. 1).

At this time, the patient needs to be instructed in the proper use of the wheelchair. Sitting schedules need to be made so as to avoid the limb being in a gravity-dependent position for a prolonged time. When not in the wheelchair, the limb should be in an elevated position to help gravity-aided swelling reduction.

An exercise program evolving the upper body and uninvolved limb needs to be implemented, and attention needs to be paid on cardiovascular fitness as well.

Many therapists evaluate the patient and see if they are cooperative; cooperative patients can start putting the foot on the ground by 3 weeks, provided they do not allow any weight on it. This helps in reducing chances of RSD.

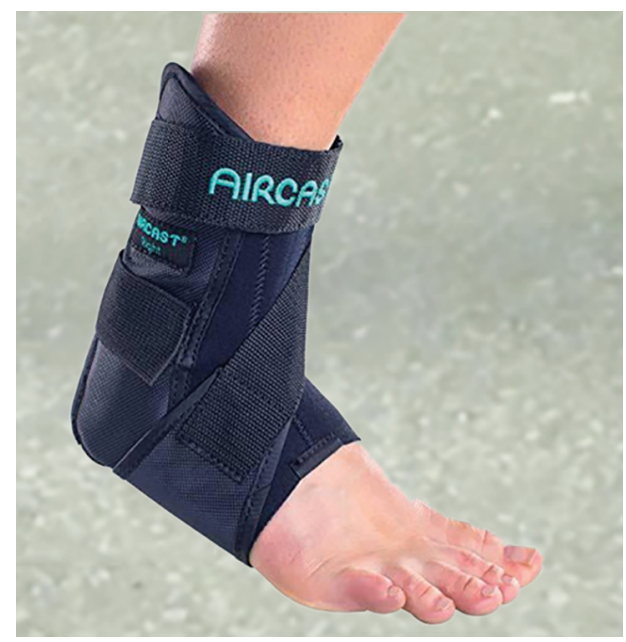

Fig. 1: Ankle support

\section{Weeks 5-8}

Goal

Control remaining edema and pain. Weight-bearing needs to be progressed slowly and safely to prevent reinjury or any complications of the fracture. Regaining ankle and foot joint motion is important to prevent contractures. Loss of function and cardiovascular endurance needs to be minimized.

\section{Precautions}

A very safe progression of weight-bearing is required. This is often guided by the patient's radiology and inputs by the treating surgeon.

\section{Interventions}

Continued elevation, icing, and compression as needed for involved lower extremity.

After 6-8 weeks, partial weight-bearing ambulation is started using crutches or walker.

Vigorous isometric and resisted exercise and range of motion is initiated to regain and maintain motion at all joints (Figs 2 to 8).

Upper extremity and cardiovascular program is monitored and further progressed.

\section{Weeks 9-12}

Goal

Progress weight-bearing. Start normal gait on all surfaces. Restorefull strength and range of motion without equinus contracture. Allow return to previous status.

\section{Intervention}

Normal full weight-bearing ambulation needs to be started with appropriate devices as required.

Special care needs to be taken of the subtler joint due to its key role in the gait cycle.

Manual joint mobilization of the subtalar joint maybe needed; tibiotalar, midtarsal, and toe joints can continue to be mobilized actively, with occasional passive manipulation.

Soft tissue mobilization of the gastrocnemius, plantar fascia, and other appropriate tissues. 


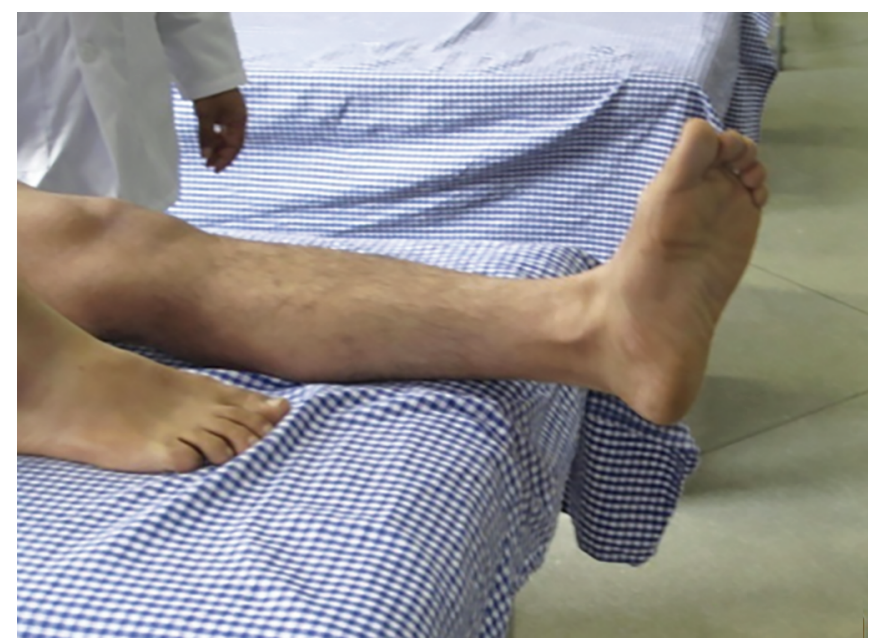

Fig. 2: Inversion exercise

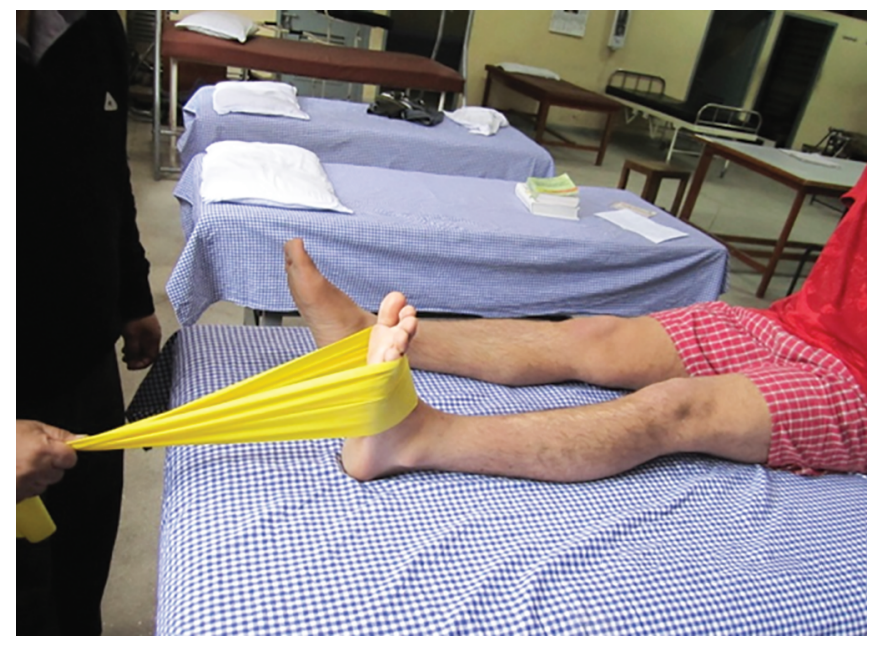

Fig. 4: Resisted strengthening of dorsiflexors

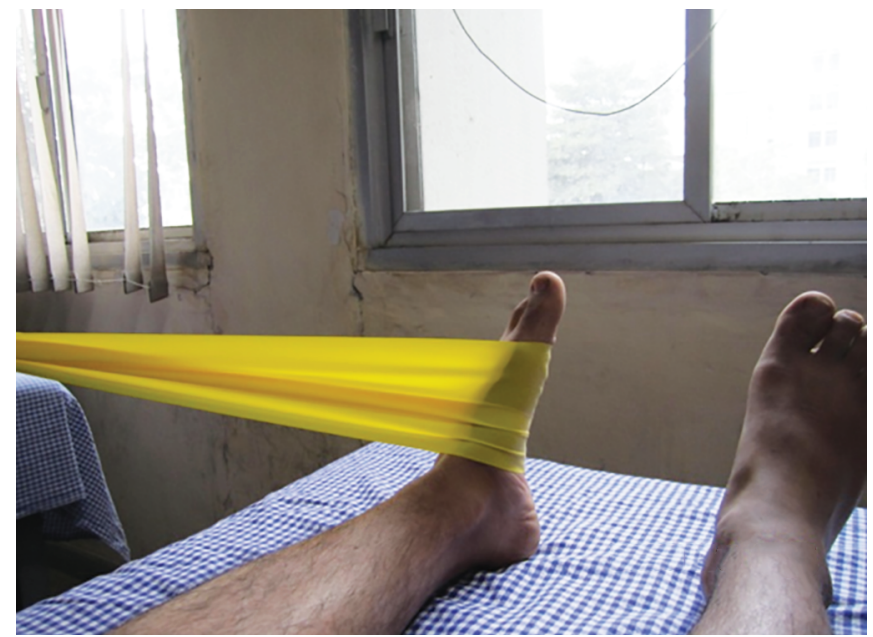

Fig. 6: Resisted strengthening of invertors

Progressive strengthening of the gastrocnemius (Fig. 9) through the use of pulleys, weighted exercise, toe-walking, and ascending/descending stairs. Pool exercises can be added at this time.

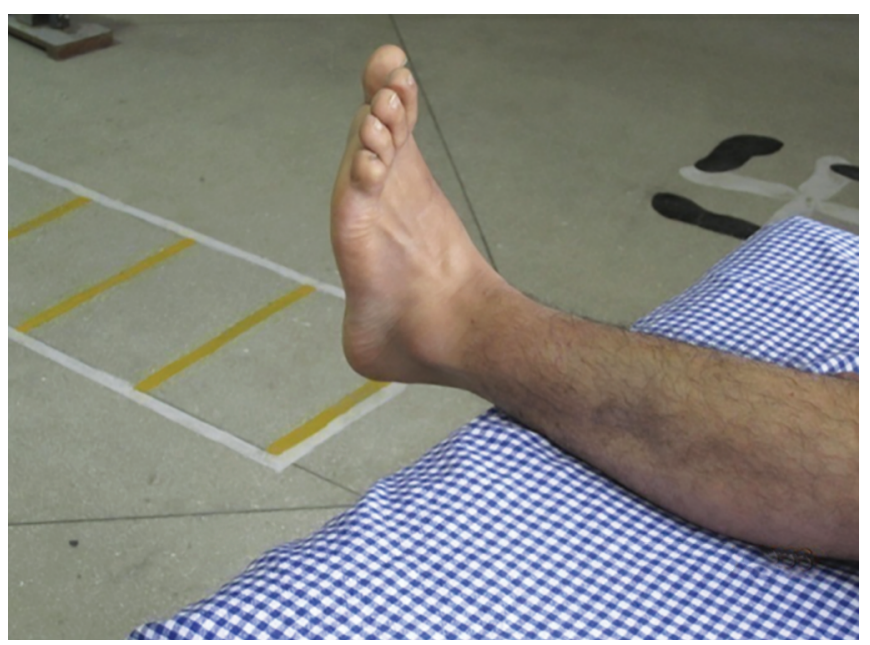

Fig. 3: Eversion exercise

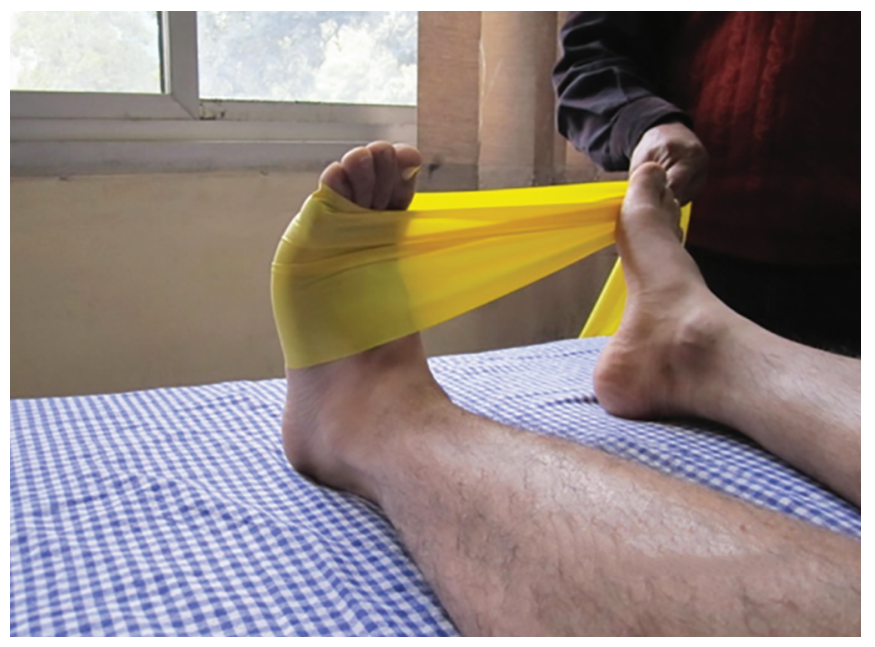

Fig. 5: Resisted strengthening of everters

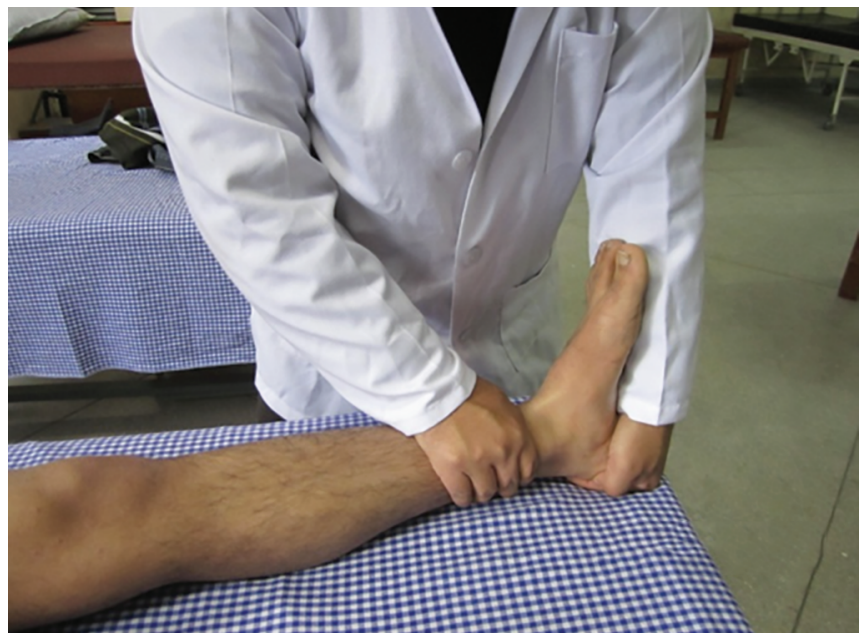

Fig. 7: Joint mobilization techniques

Skipping or other proprioception and plyometric exercise (Figs 10 and 11), including climbing activities, should resume when there is no pain or tenderness, and are again dependent on radiological progression of healing. 


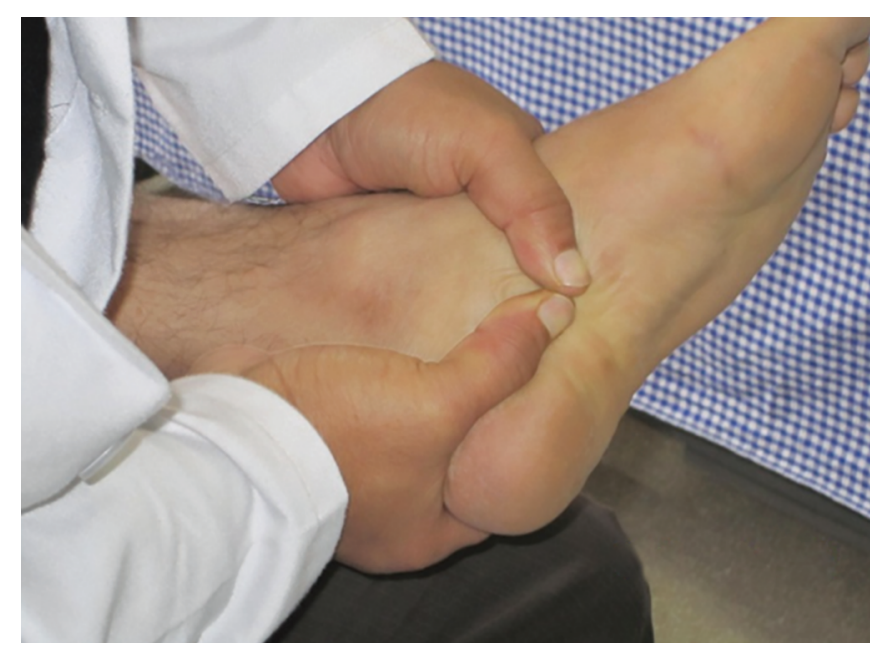

Fig. 8: Subtalar mobilization

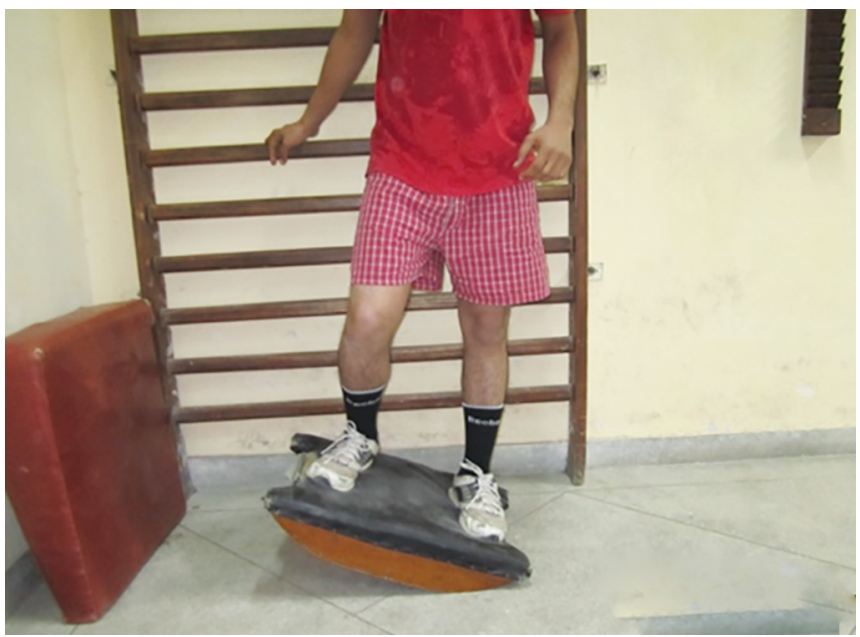

Fig. 10: Proprioceptive training

\section{Precautions}

Plyometrics should be started after complete healing of bone.

\section{Protocol for Operatively Managed Patients $^{13}$}

\section{Day 1}

The foot is wrapped in bulky bandage and splinted at the time of surgery, and the leg is elevated; pain control is done medically. The patient should be warned about numbness in foot for 12-24 hours (due to regional anesthesia). Usually, there is a drain in situ, but if not blood soakage through the bandage maybe seen, the patients should know about it. No mobilization out of bed is planned.

\section{Days 2-7}

Instruction about use of crutches, walker, and wheelchair have to be given. Dressing/splint changes are as per surgical protocol. Important to elevate the leg in the first 2 weeks, and with removable splints, foot joint mobilization should be initiated, with care to prevent equinus. Wound care takes precedence.

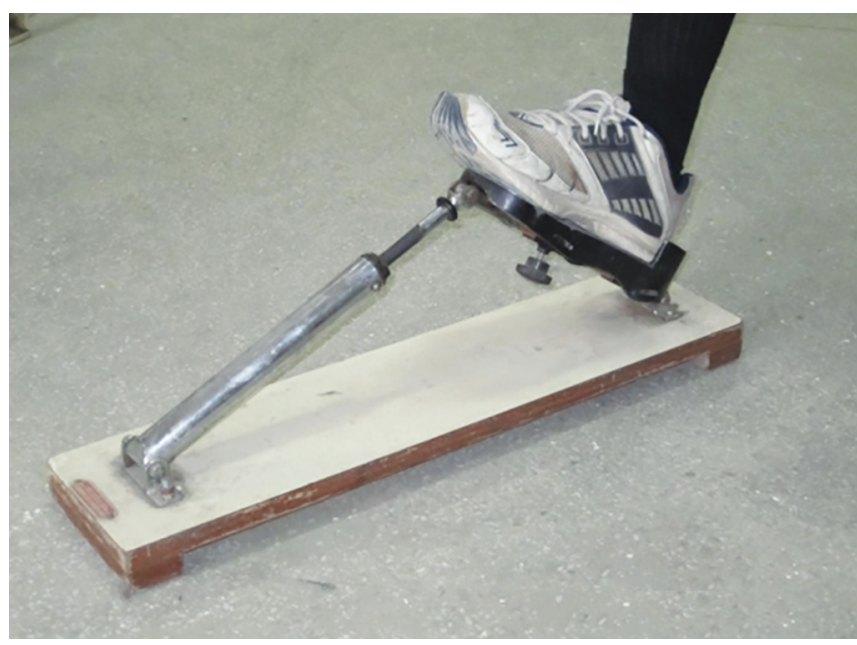

Fig. 9: Spring exercise

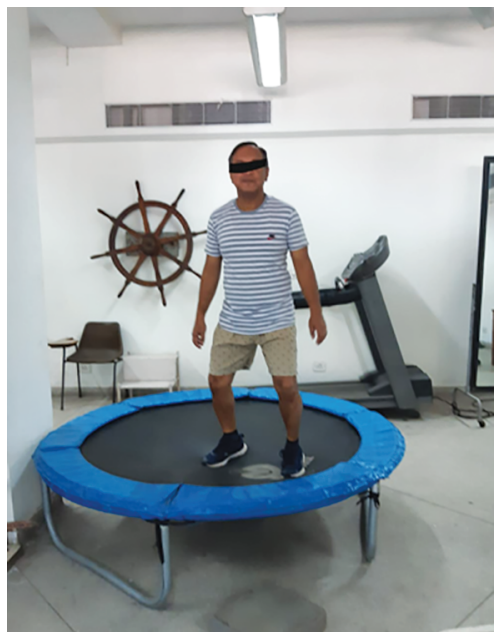

Fig. 11: Mini-trampoline exercise

\section{Weeks 2}

First follow-up in physio-outpatient department. Dressing are usually changed, and sutures may be removed. A removable boot/ brace is applied at this stage, and the physio starts motion out of the boot. Patients can wet the foot at this stage, provided the incision is clean and dry. Do not soak the foot until the incision is completely dry, i.e., about 3 weeks or more in extensile approaches. Patient is mobilized while toe-touching weight-bearing.

\section{Weeks 3}

Where available, pool exercises with some weight-bearing can be initiated; there should be no discomfort or pain, and weight of the foot is ideally avoided.

\section{Weeks 8}

Start exercise bicycle (Fig. 12), with care, and with brace in situ. Partial weight-bearing can begin, depending on quality of bone and stability of fixation, considering patient factors like obesity, ability to control locomotion, extent of understanding of the situation as well degree of cooperation. 


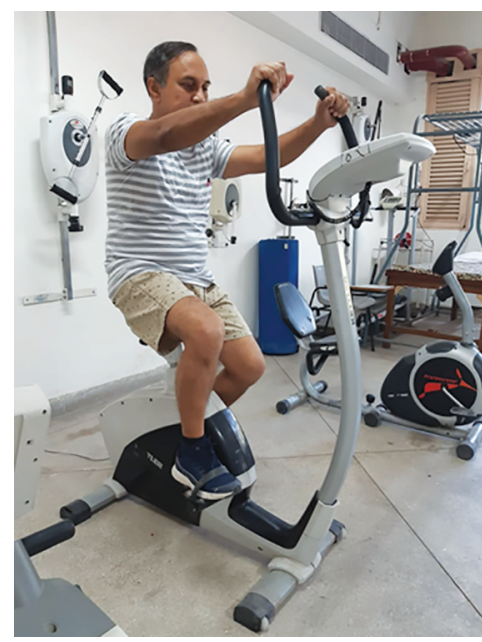

Fig. 12: Stationary cycling

\section{Weeks 10-12}

Radiological healing and the surgeon decide the status of full weight-bearing (FWB); it should be initiated with the brace/boot in situ and could progress to FWB without boot/brace depending on the patient.

\section{Precautions}

Full weight-bearing should ideally be started by around 3 months to minimize osteopenia and to strengthen the bone.

\section{Calcaneal Stress Fracture}

This is a different entity and is usually an undisplaced fracture, with minimal involvement of the joint. Calcaneal stress fractures are seen in soldiers and athletes who are involved in jumping and running are very commonly affected. Stress fractures can be of two types; fatigue stress fractures, which occur due to abnormal forces acting on normal bone structure, and insufficiency stress fracture, which occurs due to normal forces acting on abnormal bone structures. ${ }^{16,17}$ Metabolic bone diseases may also lead to stress fractures. Calcaneal fractures are second most common tarsal fractures following the navicular.

The two common sites are the upper posterior margin of the calcaneus and inferiorly where the calcaneal spur occurs. ${ }^{18}$

Timely diagnosis is very important as that allows early rehabilitation. Normally, when there is heel pain diagnosis is usually aimed at plantar fasciitis or bone spurs. ${ }^{16}$ But when the clinical findings do not match the assumed diagnosis, a more thorough investigation is required. X-rays may or may not be helpful in diagnosis depending on the stage of the fracture. The most reliable tool for diagnosis is MRI, as it detects the early changes of the osseous stress injury. ${ }^{18}$

Periodization is the key to rehabilitation in stress fractures. Periodization, in these cases, is the staged progress of the patient toward full return to pre-injury activity. This involves increasing the load slowly and as tolerated by the patient. Since stress fractures of the calcaneus have a low risk of displacement or nonunion, a graded protocol can be comfortably used. The protocol can be started by nonweight-bearing or weight-bearing activities depending on the individual and the underlying pain. If the underlying pain is severe, then a nonweight-bearing cast or orthosis is used for

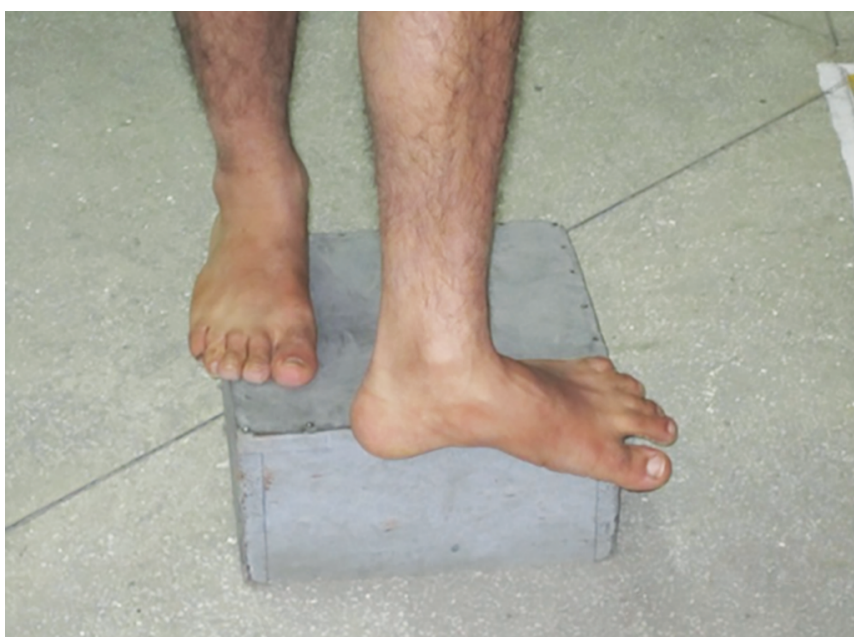

Fig. 13: Eccentric exercise for inverters

6 weeks. Following this, a graded running program is started as per the tolerance of the individual.

Calf stretches and plantar fascia along with joint mobilization are very important. Soft heel pads also assist in the shock absorption and can help with the rehabilitation. In athletes with Calcaneal stress fractures, additional coaching in the sport may be required for technique correction to prevent further injury.

Return to play is usually between 6 weeks and 8 weeks provided union is progressing well and pain relief is adequate.

\section{Early Rehabilitation (Weeks 0-6)}

NWB-PWB with crutches and protective boot/bracing is started at presentation. Cryotherapy to reduce edema and swelling are initiated as per standard protocol, although less swelling is expected here. Gradual ROM exercises of all the joints of the foot and ankle are initiated, and pain is much less than in acute trauma. The physiotherapist defines the number of sets needed, as well as the repetitions. Hydrotherapy, patient education, and activity modification proceed similar to the other protocol.

\section{Precautions}

Too early weight-bearing may slow progress if there is undue pain; a gradual progression from NWB to partial weight-bearing is recommended.

\section{Advanced Rehabilitation Phase (Weeks 6 AND ABOVE)}

A gradual increase in weight-bearing to full weight-bearing is encouraged at this stage; some patients may be comfortable while wearing an ankle support. Modalities like contrast bath, paraffin wax bath, ultrasonic therapy, soft tissue massage, and hydrotherapy are all aids that could hasten recovery. Strengthening exercise for foot and ankle muscles (Therab and/elastic band, Springs) (Figs 4, $5,6,9$ and 13) should be started at this stage, along with stretching protocols (Fig. 14), balance, and proprioception exercises (e.g., balance board) (Figs 10 and 11).

Return to normal lifestyle and activities is much faster in this group compared to traumatic injuries. 


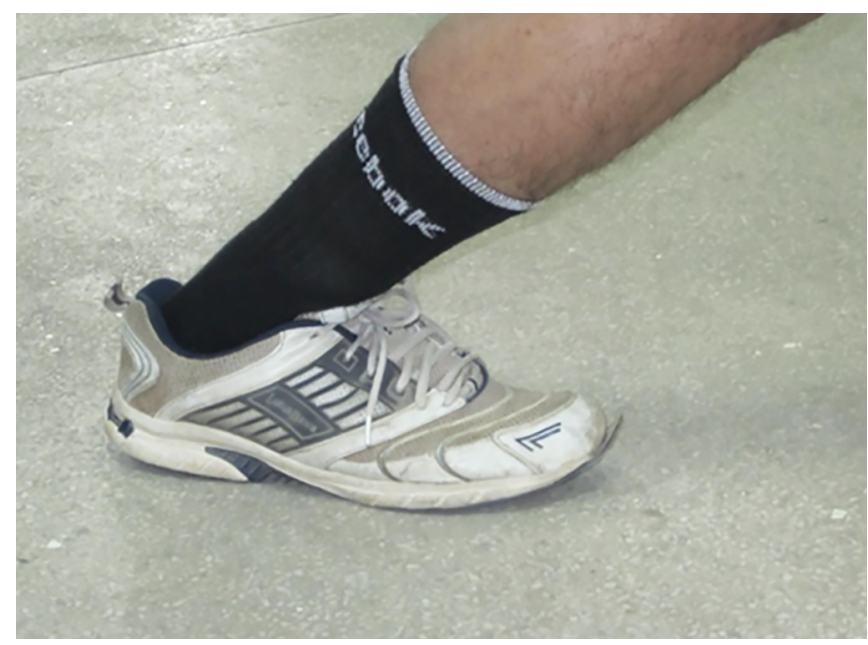

Fig. 14: Stretching of plantarflexors

\section{Bilateral Calcaneal Fracture and Cases With Associated Spine Injuries}

The calcaneus provides the foundation and support for the body to carry weight. The intra-articular calcaneal fracture usually occurs due to fall from a height or an impact on a hard surface while jumping. Calcaneal fractures commonly takes place in younger adult population. Compression fractures of the lumbar vertebrae might take place with a calcaneal fracture. Inability to or difficulty weight-bearing makes the patients ambulation difficult. These patients are treated with traditional immobilization in the form of a short leg plaster cast, or early mobilization with nonoperative management. ${ }^{14,15}$

The individuals who sustain calcaneal injury bilaterally faces additional problems while ambulation and to regain ROM, not only that if spinal fracture takes simultaneously rehabilitation is more challenging and lengthy.

Special considerations for bilateral calcaneal fracture and with spine fractures are depicted in Table 1.

\section{References}

1. Prentice WE. Rehabilitation techniques for sports medicine and athletic training. 4th ed., New York: McGraw Hill; 2004.

2. Degan TJ, Morrey BF, Braun DP. Surgical excision for anterior-process fractures of the calcaneus. J Bone Joint Surg Am 1982;64(4):519-524.

3. Pozo JL, Kirwan EO, Jackson AM. The long-term results of conservative management of severely displaced fractures of the calcaneus. J Bone Joint Surg Br 1984;66(3):386-390.

4. Essex-Lopresti P. The mechanism, reduction technique, and results in fractures of the oscalcis. Br J Surg 1951;39(157):395-419.

5. Bohler L. Diagnosis, pathology, and treatment of fractures of the oscalcis. J Bone Joint Surg 1931;13(1):75-89.

6. Burdeaux B. The medial approach for calcaneal fractures. Clin Orthop Relat Res 1993(290):96-107.

7. Palmer I. The mechanism and treatment of fractures of the calcaneus. J Bone Joint Surg 1948;30A(1):2-8.

8. Parmar $\mathrm{H}$, Triffitt $\mathrm{P}$. Intra-articular fractures of the calcaneum treated operatively orconservatively. J Bone Joint Surg 1993;75-B(6):932-937.
Table 1: Special considerations for bilateral $(\mathrm{B} / \mathrm{L})$ calcaneal fracture and with spine fractures

\begin{tabular}{|c|c|}
\hline Bilateral calcaneal fractures & $\begin{array}{l}\text { Bilateral calcaneal fractures with } \\
\text { spinal fractures }\end{array}$ \\
\hline $\begin{array}{l}\text { Wheel chair mobility is the } \\
\text { early mode of ambulation. }\end{array}$ & $\begin{array}{l}\text { Maintaining neutral spine position } \\
\text { during sitting in wheel chair and } \\
\text { walking (when PWB is permitted) } \\
\text { activities, a TLS brace can be used. }\end{array}$ \\
\hline \multirow[t]{2}{*}{$\begin{array}{l}\text { Careful bed mobility and } \\
\text { transfer to avoid weight- } \\
\text { bearing. }\end{array}$} & $\begin{array}{l}\text { Proper bed mobility, positioning } \\
\text { with pillows under/between legs, } \\
\text { and transfers (log roll) need to be } \\
\text { taught. prolonged sitting and car } \\
\text { rides to be avoided. Lumbar roll can } \\
\text { be used while sitting. }\end{array}$ \\
\hline & $\begin{array}{l}\text { Educate on proper sitting ergonom- } \\
\text { ics in the wheel chair and car. Avoid } \\
\text { bending, lifting and twisting. }\end{array}$ \\
\hline $\begin{array}{l}\text { Ankle pumps, glutei, and } \\
\text { quadriceps sets to help with } \\
\text { circulation should never be } \\
\text { missed. }\end{array}$ & $\begin{array}{l}\text { Ankle pumps, glutei, and quadri- } \\
\text { ceps sets to help with circulation } \\
\text { should never be missed, emphasis } \\
\text { on deep breathing exercises. }\end{array}$ \\
\hline \multirow[t]{2}{*}{$\begin{array}{l}\text { Ambulation progression as } \\
\text { tolerated; initially with wheel } \\
\text { chair, partial weight bear- } \\
\text { ing with assistive device like } \\
\text { walker with main support } \\
\text { from upper extremity when } \\
\text { tolerated. }\end{array}$} & $\begin{array}{l}\text { Ambulation progression as toler- } \\
\text { ated; initially with wheel chair, } \\
\text { partial weight bearing with assistive } \\
\text { device like walker with main sup- } \\
\text { port from upper extremity when } \\
\text { tolerated. }\end{array}$ \\
\hline & $\begin{array}{l}\text { Normalize gait and postural } \\
\text { mechanics. }\end{array}$ \\
\hline
\end{tabular}

9. Paley D, Hall H. Calcaneal fracture controversies-can we put humpty dumpty togetheragain? Clin Ortho 1989;20(4):665-677.

10. Wei S, Okereke E, Esmail A, et al. Operatively treated calcaneus fractures:to mobilize or not to mobilize. Univ of Penn Ortho J 2001;14:71-73.

11. Barnard L, Odegard J. Conservative approach in the treatment of fractures of the calcaneus. J Bone Joint Surg 1955;37A(6):1231-1236.

12. Godges J, Klingman R. Calcaneal Fracture and Rehabilitation Surgical Indications and Considerations Anatomic Considerations. Loma Linda U DPT Program KPSoCalOrthoPTResidency1;cited2010-11-12. Available from: http://xnet.kp.org/socal_rehabspecialists/ptr_ library/09footregion/31foot-calcanealfracture.pdf.

13. Redfern DJ, Bendall SP. Fracture of the Calcaneus: Open Reduction and Internal Fixation. Sussex,UK: Sussex Foot and Ankle Centre; 2009. Available from: http://www.sussexfoot.com/.

14. Sharr PJ, Mangupli MM, Winson IG, et al. Current management options for displaced intra-articular calcaneal fractures: non-operative, ORIF, minimally invasive reduction and fixation or primary ORIF and subtalar arthrodesis. A contemporary review. Foot Ankle Surg 2016;22(1):1-8.

15. Walters JL, Gangopadhyay P, Malay DS. Association of calcaneal and spinal fractures. J Foot Ankle Sur 2014;53(3):279-281.

16. Weber J, Vidt L, Gehl R, et al. Calcaneal stress fractures. Clin Podiatr Med Surg 2005;22(1):45-54.

17. Brukner P, Khan K, Clarsen B, et al. Clinical Sports Medicine. 3rd ed., North Ryde NSW: McGraw Hill; 2005.

18. Pegrum J, Dixit V, Padhiar N, et al. The pathophysiology, diagnosis, and management of foot stress fractures. Phys Sportsmed 2014;42(4): 87-99. 